\title{
SOME DANGERS IN THE FIRST MONTH OF LIFE.
}

\author{
By I. ROSE, M.B., Ch.B., D.R.C.O.G.
}

(Medical Officer in Charge, St. Helen Municipal General Hospital, Barnsley.)

The neo-natal period is the first month of infant life. Why does one pay such attention to this particular period? Statistics show that the infant mortality rate (i.e., the number of infants who die in the first year of life per $\mathrm{I}, 000$ live births in that year) has been more than halved since I900.

For example :

the infant mortality rate from I9OI-I905 was I38 per I,000 live births, whereas the infant mortality rate from I937-I938 was 58 per I,000 live births.

However, the death rate amongst infants during the first month of life has been reduced very little indeed, and these neo-natal deaths represent almost one-half of the infant mortality rate. That is to say, almost half the infants who die in the first year of life, die in the first month.

From recent statistics (vide U.S. Public Health reports, I940), the extent to which neo-natal mortality varies in different places may be shown as follows:-

Neo-Natal Mortality. Rate per 1,000 live births, 1938.

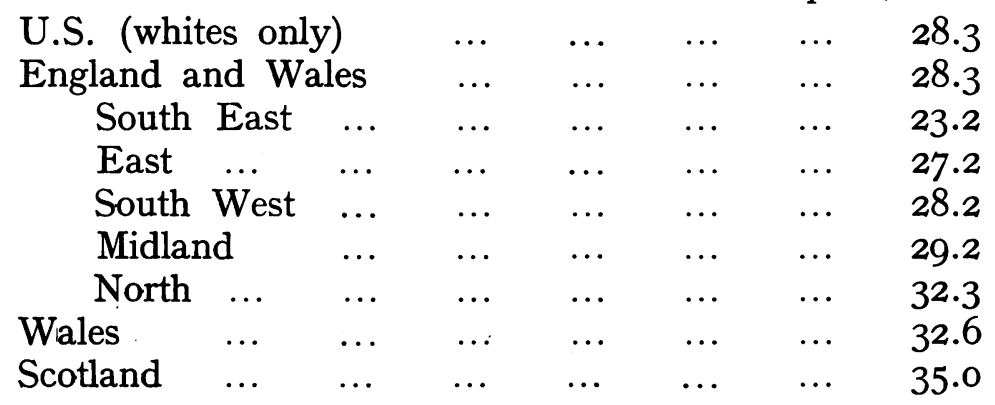

The differences are substantial and indicate that there is scope for a material reduction of the rates in higher ranges. This is further emphasised by the fact that in Adelaide, S. Australia, the neo-natal mortality rate was 20 in 1936, while in Amsterdam (Holland) and Göteburg (Sweden) it was as low as I6 in I937 (McNiel, 1940).

Of neo-natal deaths 35 per cent. occur within 24 hours of birth and another 37 per cent. occur within Ist week.

Moreover, 77 per cent. are certified in the category of Developmental and Wasting Diseases, and reference to the certified causes of death show that these are stated as :-
I. Premature birth,
2. Marasmus,
3. Atelectasis,
4. Congenital deformities.

The remaining 23 per cent. of cases are made up of Birth injuries and infection. 


\section{Prematurity.}

I. Twin pregnancies account for 15 per cent.-25 per cent. of cases.

2. Breech pregnancies account for ro per cent.-20 per cent. of cases.

3. Syphilis accounts for only about 3 per cent.

4. General Maternal causes.

Toxæmias-e.g., pre-eclamptic toxæmia.

Chronic nephritis-not as common a condition complicating pregnancy as was heretofore considered.

Heart disease.

Phthisis.

Acute infectious fevers.

Lead poisoning-(i.e., attempts at criminal abortion with lead pills and diachylon plaster).

Severe anæmias.

5. Illegitimacy.

6. Ante-partum hæmorrhage--placenta prævia, accidental hæmorrhage (which is associated with pre-eclamptic toxæmia).

7. Surgical Induction for minor and medium degrees of pelvic contraction, from 36 th week onwards.

This procedure is now rapidly losing favour in this country because of the high fotal mortality, and is being replaced by trial labour, or elective Cæsarian section at term.

8. Unknown.

In a series of 437 cases of prematurity studied by Capper, 60 per cent. were of unknown ætiology. Recently, however, the condition of erythroblastosis fotalis has come into prominence, and may manifest itself in one of three ways, viz.:-

(a) Hydrops fotalis-with universal œdema, usually still-born.

(b) Severe hæmolytic anæmia of the newly born.

(c) Icterus gravis neonatorum (grave familial jaundice).

For those interested in this subject, I should recommend reference to Hawksley and Lightwoods (r934) excellent paper.

The factors which influence the prognosis in PREMATURITY.

I. The chance of survival is directly proportional to:-

(a) Age of the fœtus,

(b) Its birth weight.

(a) is more important, for a small infant born near term is more likely to survive than a larger infant born more prematurely.

2. The likelihood of survival is affected by the health of the mother during her pregnancy. For example, if associated with eclampsia, syphilis or acute infectious fevers, there is less chance than if prematurity is due to twins. doubled.

3. If illegitimacy is associated with prematurity the infant mortality is almost 
4. The soft plastic head of a premature infant is more susceptible to injury during its birth. Thus prolonged labour in primagravidae may cause a cerebral hæmorrhage. Further, if a forceps extraction becomes necessary, the fotal mortality is very high.

5. Premature infants are more likely to develop ancmia and rickets, since the fœtal storage of calcium and iron is laid down chiefly in the last three months of pregnancy. This deficiency of calcium and iron renders the premature infant more prone to infections, particularly of the respiratory and gastro-intestinal tracts.

6. Whether adequate care is given:-Warmth, nourishment, prevention of infection, Careful nursing are important factors.

\section{The management of a premature baby.}

For those cases which cannot be treated adequately at home or are losing ground, hospitalization is essential. Dr. J. L. Burn, our Medical Officer of Health, has inaugurated a "premature cot service" as part of the Emergency Maternity Services for Barnsley. When a premature child is to be admitted to hospital, the ambulance is instructed to call first at the hospital to collect a premature cot, blanket lined and containing three guarded hot-water bottles at the proper temperature (see below) and, with a nurse, the ambulance proceeds to the home of the infant, when the latter is carefully placed in this warmed cot and taken into hospital. The mother is taken into hospital at the same time, for the purpose of breast feeding.

In the management of a premature baby; the following factors must be observed :-

\section{Warmth.}

Immediately after birth cover the child with warm wool and put it in a warm place.

It must not be bathed, but gently oiled all over with warm olive oil, beginning six hours after birth, and repeating every other day.

The room temperature should be about $70^{\circ} \mathrm{F}$, but during oilings should be raised to $75^{\circ} \mathrm{F} .-80^{\circ} \mathrm{F}$.

The rectal temperature should be taken every four hours and charted, using a special thermometer registering low temperatures. The rectal temperature should be between $98^{\circ} \mathrm{F}$. and $99^{\circ} \mathrm{F}$.

The cot should be blanket-lined, and have three hot-water bottles-one at the foot at $180^{\circ} \mathrm{F}$. and one at either side at $160^{\circ} \mathrm{F}$. These bottles should be changed hourly.

An alternative to the hot-water bottle method is the use of an electric heating pad, which we have employed successfully. Any good make can be used: e.g., "Thermega" or "Milliwatt" - there are three degrees of heat, and these pads cannot overheat as they are equipped with automatic thermostats. The infant is first wrapped in a blanket, and the electric pad is placed over the child like an eiderdown cover over a bed.

\section{Clothing.}

The body and limbs should be wrapped in cotton wool.

Apply a crepe bandage binder until the cord has separated.

Use a woollen jacket which opens up the front. 
Cover the legs with a flannel wrap-over.

Protect the head by a flannel bonnet, the face only being left free.

Instead of an ordinary napkin, a square of absorbent wool, should receive the discharges.

A soft woollen shawl should be wrapped completely around the baby.

The infant should be disturbed as little as possible, although gentle changes of position every now and then will assist proper ventilation of the lung; thus, the child's position can be changed before every feed.

Watch should be kept for cyanotic attacks, and a mixture of $95 \%$ oxygen and $5 \%$ carbon-dioxide gas should be given in a gentle stream bubbled through warm water via a nasal catheter (lubricated with liquid paraffin).

\section{Feeding.}

Breast milk is the best, and every effort should be made to secure this, either from the mother or from another patient. It would be an advantage to have "breast milk banks" available in the same way as "blood banks," whereby breast milk could be readily available in cases of necessity.

The normal infant requires 45 calories per lb. body weight per 24 hours for its metabolic needs, but the premature child requires much more than this figure (6o-8o calories per lb. body weight). It is important however to increase gradually to the adequate amount, which may take $2-3$ weeks. There is a great danger of overfeeding, for the digestion is feeble, and if food is forced the life of the child will be jeopardised by digestive upsets. Therefore, always begin with a small quantity of food, find the infants' tolerance, and increase with caution. If the infant is too feeble to suck, give the feeds with a pipette, dripping the milk slowly onto the back of the tongue. If the infant is very feeble it may be inclined to choke, so that it may be safer in such cases to pass a small catheter ( 3 or 4 English size) into its stomach, allowing three minutes for the milk to pass into the stomach. Measure the distance from the root of the nose of the infant to the xiphisternum and mark this distance on the catheter by means of a piece of white cotton. The catheter is sterilized before passage, and is easy to pass-there is no danger of getting the tube into the trachea. This is the method of "gavage," and it should be only necessary to use it for a few days until the infant can swallow properly. From experience, it is found that about I drachm at each feed is as much as the infant will tolerate at first.

For the first day feed three times only; for second day, I-hourly feeds by day, and 2-hourly by night (i.e., I8 feeds in all). Increase the feeds by half a drachm every other day, so that by the end of the Ioth day, each feed will be about 3 drachms in quantity. A careful watch should be kept for signs of overfeeding which are: regurgitation of feed, vomiting, diarrhœe, or cyanotic attacks after feeds. At about the end of the second week it should be possible to lengthen the intervals between the feeds giving: 2-hourly feeds by day and 3-hourly feeds by night (i.e., Io feeds in all per 24 hours). By the end of the lhird week the amount should be worked up to one ounce per feed, without relaxing the watch against overfeeding. When the feeds have been worked up to Io ounces per 24 hours this amount should be persisted with, until the weight begins to falter. At this stage, increase by one drachm each day until rise in weight is 
resumed. When the weight has reached $7 l b$. 3-hourly feeding should begin, leaving out one feed at night (i.e., 7 feeds per 24 hours).

If breast milk is unavailable, a good substitute is Marriott's lactic acid milk, prepared as follows:-Boil cow's milk and allow it to cool. Add lactic acid (B.P. strength) drop by drop, stirring the whole time, in the proportion of I drachm of lactic acid to I pint of milk. Then add $\frac{1}{2}$ to I ounce of lactose per pint of milk. Warm to body heat before feeding, and proceed as for breast milk.

\section{Prevention of Infection.}

To prevent infection, practice strict asepsis at the time of birth, and see to scrupulous cleanliness in nursing. Nurses in charge must be free from any respiratory catarrhs and infants should be nursed in a room by themselves away from other children. The room should be well-ventilated, but the cots must be screened from draughts, and all entering the room must wear face masks and gowns. Close admiration of the baby by relatives must be prohibited.

Give from the end of the first month Ferri et Ammon. Cit. Gr. I. in 2 feeds per day and Cod Liver Oil emulsion $\frac{1}{2}$ drachm twice daily or "Haliborange" 2 drops daily.

\section{Marasmus or Wasting.}

Be sure that there are no associated signs of congenital syphilis. Remember that stigmata of congenital syphilis may not appear for several weeks after birth. Suppose a normal breast-fed infant is losing weight, the adequacy of the breast milk can be decided by test feeding, and it is best to ascertain the total amount of milk secreted for the whole of the $\mathbf{2 4}$ hours -it is obvious that a single feed, usually "tested" in the afternoon, will give no proper idea of the total milk taken during the day. Correlate the amounts taken by the infant with its calorific requirements for its weight (see below in discussion on calorific values).

If the breast milk is inadequate the following measures should be taken to try and increase the amount:-

I. Put baby to the breast every three hours, ro minutes each side.

2. Drink a glass of water every time before feeding baby.

3. After baby has finished sucking, squeeze as much milk as possible from the breasts, or else use a breast pump.

4. Bathe the breasts twice daily, first with hot and then with cold water. Afterwards rub briskly towards the nipple with a rough towel.

5. Be out in the fresh air as much as possible every day.

6. Eat three good meals a day. These should include-if possible-porridge, fruit, vegetables, butter or dripping, eggs, and about a pint of milk.

7. You should take a rest with your feet up for an hour each day after dinner. This is most important.

If necessary, complementary feeding may be instituted. If the infant is being artifically fed be sure that the diet is a properly balanced one and is adequate for the infant's calorific requirements. Many infants' lives are lost through wrong 
artificial feeding, although with the improved maternity and child welfare services, this fault is being remedied. Cases are met with of so-called "scientific starvation" e.g:, where a watery solution of cow's milk was given most meticulously in the proportion of 2 ounces of milk to I pint of water. This is insufficient for the needs of a baby mouse, let alone a human infant!

At this stage it would be advisable to determine whether the infant is being given an adequate supply of food for its calorific requirements.

A newly born infant requires $45-50$ calories per lb. body weight per 24 hours, and $2 \frac{1}{2}$ ounces fluid per $\mathrm{lb}$. body weight per 24 hours.
I ounce cow's milk
I ounce human (breast) milk
I drachm (I heaped up teaspoonful) of full cream milk powder
I drachm (I heaped up teaspoonful) of $\frac{1}{2}$ cream milk powder is equivalent to I2 calories.

From these data one is able by a process of simple mental arithmetic, to deduce whether the infant is obtaining sufficient food. For example, take a child of $6 \mathrm{lbs}$. weight at birth. It requires $6 \times(45-50)$ calories 300 calories roughly. Assume it is fed 3 -hourly $(6,9,12$ noon, 3,6 and 9 p.m.) i.e., 6 feeds per 24 hours. The infant will require $300 / 6$ calories per feed $\equiv 50$ calories per feed. Hence if a full cream milk powder is used $2 \frac{1}{2}$ drachms are required per feed.

In addition, the fluid requirements must be remembered, as insufficient fluid will cause dehydration fever in the newly born. For this infant, $6 \times 2 \frac{1}{2}$ fluid ounces are necessary for 24 hours. For each feed, $\frac{6 \times 2 \frac{1}{2}}{6}$ ounces are required $\equiv 2 \frac{1}{2}$ ounces fluid. Hence for each feed add $2 \frac{1}{2}$ ounces of boiled and then cooled water to $2 \frac{1}{2}$ drachms of the milk powder, warm to body heat, etc.

Moreover, the simple calculation can be applied to test-feeding in order to determine whether the child is obtaining adequate breast milk for its calorific requirements.

A normal infant probably cannot be overfed (as distinct from a premature infant, as discussed earlier). Confusion still exists in some minds between possetting and vomiting. Possetting is due to air-swallowing, and the infant does not really vomit but regurgitates. Notice the dyspeptic expression of the infant's face (like the wry Charlie Chaplin expression) just prior to possetting, due to gaseous distension of its stomach. Gently pat or rub the infant's back, and it will be found that the infant brings up gusts of wind. Unfortunately this possetting is confused with vomiting - it is then decided that the child is being overfed, with the results that its feeds are cut down, and the child begins to lose weight-or it may be thought that the food is not "agreeing" with the infant, and changes are made from one proprietary brand to another.

A further important practical point is to see that the hole in the teat is not too fine. I have met cases from time to time where the infant "will not take its feeds," due to too fine a teat aperture. I have asked the nurse looking after the infant to test this teat by sucking at it herself and she is amazed to find that her own well-developed sucking muscles are unable to force the milk through a fine aperture. 


\section{Atelectasis.}

This is a non-expansion of the solid fœtal lung, and it is intimately associated with the question of asphyxia neonatorum, which may manifest itself as blue asphyxia (asphyxia livida) or white asphyxia (asphyxia pallida).

In either case, attempt no heroic measures at artificial respiration. Handle the infant carefully. Cleanse the air passages carefully, using mucus catheter if necessary. Apply warmth by means of carefully guarded hot water bottles.

Elevate the foot of the cot $I 5^{\circ}$, so that mucus or liquor amnii is not aspirated into the bronchi when the child takes its first breath. Give oxygen and carbon dioxide by an intranasal catheter if necessary. There is an excellent film on this subject by Dame Louise McIlroy, issued by the lending library of the Kodak Film Co.

\section{Congenital Deformities and Malformations:-}

These are divided into three groups, viz.:-

(A) Those for which little can be done.

$$
\text { e.g. }\left\{\begin{array}{l}
\text { morbus cordæ. } \\
\text { spina bifida. } \\
\text { meningocele. } \\
\text { hydrocephalus. } \\
\text { monstrosities. } \\
\text { exophthalmos. }
\end{array}\right.
$$

(B) Those in which a child's life may be saved by timely recognition.

$$
\text { e.g. }\left\{\begin{array}{l}
\text { imperforate anus and rectum. } \\
\text { imperforate urethra. } \\
\text { congenital pyloric stenosis. }
\end{array}\right.
$$

(C) Those which should not pass unrecognised, as with early treatment the infant is saved much disability or suffering later.

$$
\text { e.g. }\left\{\begin{array}{l}
\text { phimosis. } \\
\text { inguinal hernia. } \\
\text { umbilical hernia } \\
\text { congenital talipes. } \\
\text { Erb's palsy. }
\end{array}\right.
$$

These congenital malformations are factors over which we have no control ante-natally. Some of these may show on X-ray examination in the antenatal period, but it is problematical whether a routine X-ray examination should be done in every pregnancy to eliminate gross deformity.

\section{Birth Injuries and Infection.}

Birth Injuries are due to:-

Difficult labours.

Delayed labour.

Obstructed labour.

Malpresentations.

Breech delivery. 
Although birth injuries are often attributed to obstetric difficulties, it would be more precise to consider them as due to a combination of obstetric difficulties and lack of timely skilled assistance.

Complete antenatal supervision, with timely reference of doubtful cases to a consultant specialist should theoretically do away with the problems of abnormal labour. However this is too much to ask, as even with the most precise care, errors of judgment have been and will be made occasionally, e.g., in cases of suspected disproportion.

However, there is an occasional tendency for midwives in general to hold on to cases too long, and delay sending for skilled assistance. Such midwives, admittedly not common, consider that it is a reflection on their skill and prowess to send for medical aid, until it is too late.

Many of the babies dying in the first month have not lived long enough to contract infectious diseases. However, fulminating broncho-pneumonia may occur, and is often confused with overlying of the infant. Accidental overlying is very rare, and in those instances in which it is a valid diagnosis, confirmed by post-mortem, there is a strong possibility of infanticide. So much for neo-natal mortality.

Let us now consider neo-natal morbidity.

\section{Neo-Natal Morbidity.}

Sepsis is the chief bug-bear and will be considered under different headings.

Infection of the skin and mucous membranes.

The newly born child has practically no immunity against the common pyogenic organisms, and is therefore an easy prey to infection. The most common portal of entry for organisms is the raw wound at the umbilicus, but any skin abrasion may readily be infected, and those in charge of an infant may easily convey infection either with their breath by droplets of sputum, or with their hands. Owing to lack of immunity, infection which begins locally may quickly develop into pyæmia and septicæmia, and because the fighting forces on which the infant can draw are so feeble, the clinical picture is a very different one from that in adults. The local lesion may show practically no reaction, nor may there be any striking general effect, and yet the infection may already be widely disseminated. Hence we see conditions such as:-

Erysipelas.
Pemphigus neonatorum.
Impetigo contagiosa.
Thrush due to œedium albicans, conveyed from dirty bottles or
$\quad$ teats.
Eczematous dermatitis.
Burns and scalds, due to hot-water bottles not sufficinetly
$\quad$ guarded.

Syphilitic skin infection is sometimes seen, of variable appearance. Usually the basis of the rash is a blotchy erythema, coppery red in colour with scaling of the superficial layers of the skin, often seen over the buttocks, the palms of the hands and the soles of the feet. 


\section{Respiratory infection.}

This is an important group, and is often seen during periods of epidemic colds and influenza. To prevent respiratory infections, the infant must be treated with the same scrupulous care as if performing the time honoured ritual of the delivery. Hence the following points should be observed: Wearing of masks with scrupulous asepsis; isolation from the rest of the household; and non-attendance of midwives or doctors in confinement if affected with sore throat or common cold. Keep members of the household away from the child if they have common colds, skin diseases, etc.; fondling of the infant by friends and well-meaning relatives must be discouraged; and fresh air, warmth, and screening from draughts should be emphasised.

\section{Alimentary tract.}

Diarrhoea. This is a serious condition if due to infection, e.g., in summer diarrhœa of infants, where the infection gets into cow's milk. The clinical picture is well known, with sudden onset, vomiting, pyrexia which may reach I0 ${ }^{\circ}$, green watery offensive stools, depression of the anterior fontanelle, sunken eyes, wasting and dehydration.

\section{Infectious fevers.}

It is but rarely that an infant is a victim of any of the infectious fevers because it has already received some degree of immunity from its mother.

Anterior poliomyelitis: one case recorded.

Bubonic plague: very fatal.

Chicken pox: very rare.

Diphtheria: doubtful whether true diphtheria occurs.

Encephalitis lethargica: very rare.

Influenza : may occur.

Measles

German measles $\}$ Infant is immune to these conditions.

Scarlet fever

Smallpox

Typhus

Yellow fever

may occur.

\section{Ophthalmia neonatorum :-}

May be due to the gonococcus, or hæmolytic streptococcus, pneumococcus, B.Coli, or Koch-Weeks bacillus (a "weak" diphtheroid organism). The eyes of the child are, in the vast majority of cases infected during delivery in the second stage of labour. They may be contaminated by the nurse or the mother after birth, in which case the conjunctivitis may supervene as late as the sixth day.

The danger lies in the fact that the midwife in charge of such a case tries to "hold on" too long, hoping to cure the child herself by instilling drops perhaps twice or thrice at the most per day. In this respect, it must be remembered that it is not always the fault of the midwife that a child develops ophthalmia neonatorum, as the most careful ritual of bathing the eyes and instilling drops may be observed at birth and yet the infant may develop purulent conjunctivitis later. An illustrative example is the case of A.C., a primigravida, who was admitted to 
hospital on 9.6.39. for medical induction as the head was a large diameter. She went into labour after medical induction and the labour was prolonged though normal. I delivered the infant myself, and saw to the careful treatment of the child's eyes shortly after birth. This child developed a purulent conjunctivitis on the third day of the puerperium, which cleared up satisfactorily with intensive treatment. This same woman was re-admitted to hospital on 29.7.40, in her second pregnancy (5 months pregnant) for the treatment of a severe vaginal discharge. The latter was undoubtedly responsible for the purulent conjunctivitis in her first infant. A cervical swab on examination showed the presence of epithelial debris, pus, gram positive cocci, gram positive bacilli, and gram negative bacilli, but no gonococci. Cultures gave a growth of staphylococcus albus and coliform bacilli.

This shows the importance of careful vaginal and cervical inspection during pregnancy, and the importance of notifying all cases of purulent conjunctivitis immediately to the Supervisor of Midwives, so as to ensure early and adequate treatment. The latter is an intensive 2-hourly treatment by day and by night by a staff of nurses specially experienced in such treatment which can only be given adequately in hospital. The mother should be admitted at the same time to continue breast-feeding, and to undergo treatment of her vaginal discharge as soon as practicable in the puerperium.

Two other conditions may be mentioned lastly:-

Jaundice.

This may be physiological-the infant is not ill and takes its feeds well. It usually disappears at the end of the second week.

Infective jaundice.-Commonly arises from an infected umbilicus, and comes on the fifth, seventh or tenth day with symptoms of pyæmia or septicæmia.

Syphilitic Jaundice.-Occurs at birth. Usually associated with other syphilitic stigmata, and enlarged spleen and liver. Prognosis is grave.

Familial Icterus Gravis is of unknown causation. Deep jaundice, drowsy infant, and purpuric hæmorrhages. This is a manifestation of erythroblastosis foetalis.

Familial acholuric jaundice is present at birth, the child becomes ill and drowsy. Then the jaundice clears up and child becomes well again, but it recurs at intervals. Anæmia is a prominent feature here.

Congenital obliteration of bile ducts. Healthy child at birth. Jaundice appears about the second week, the general condition remains good for weeks, but gradually the child's weight drops, and it becomes comatose and dies. Death occurring from the third to the eighth month.

\section{Hamorrhagic disease of the new born.}

Common symptoms are vomiting of blood and passage of blood in the stools, varying in amount from a microscopic quantity to a steady trickle of blood through the anus. Attention is usually drawn to the condition by the appearance of dark almost black stools containing altered blood (melæna neonatorum. Timely administration of 5-ro c.cs whole paternal blood intramuscularly will save the infant's life. 
Suggestions as to steps that can be taken to secure further reduction in the neo-natal mortality and morbidity rates.

I have abstracted excerpts from the excellent report by Dame Janet Campbell, on "Infant Mortality," and have added a few personal suggestions.

(1) Improvement in the general sanitary environment, and particularly in housing.

(2) The even further development of the maternity service and its ancillary branches.

(3) More efficient ante-natal supervision of the pregnant woman as regards her general health and as regards possible obstetric difficulties.

If the doctor is not responsible for the confinement, the midwife should observe closely the state of the woman through the whole period, and should call in medical aid whenever any departure from the normal is observed. It is in fact her duty to do so under the rules of the Central Midwives Board. In certain instances, the antenatal supervision is unquestionably perfunctory or insufficient. For example, antenatal supervision is sometimes interpreted merely as a more or less systematic testing of urine, and even where this is carried out, it may not be continued up to the end of the pregnancy, although we know that some of the worst cases of eclampsia show no albuminuria until shortly before labour sets in. Although measurements are taken at the first visit, no examination is made in a primigravida in the later months to investigate a possible disproportion between the head and the pelvis. Obviously the best means of safeguarding maternal and fœtal welfare is for the doctor and midwife who will undertake the confinement to be directly responsible for the ante-natal supervision throughout the pregnancy.

Hygiene of the breast and nipples is a very important factor which is often overlooked, so that a woman with retracted nipples is unable to suckle her newly born infant.

(4) Adequate attendance at the time of childbirth by well trained midwives and competent doctors, for women who prefer to be confined at home, where this can be arranged with safety.

(5) There should be more adeqụate hospital provision readily available for all abnormal or complicated cases, during and after parturition, and for all women whose homes are for any reason unfit for confinement.

(6) There should be further extension of the supplementary assistance required by a woman before, during and after childbirth, with a view to protecting and safeguarding the health of herself or her child, such as extra nourishment, monetary grants or domestic helps.

(7) The early detection of injury or disease is of the greatest importance, and all newly born infants except the extremely feeble should undergo a thorough routine examination. Only by this means can injury, disease or deformity be detected and early treatment instituted. Abrasions of the skin which might lead to fatal sepsis can be protected. Fractured bones may be immobilised. A bulging fontanelle indicating increased intracranial pressure may be relieved by lumbar puncture. Examination of the heart may reveal a congenital defect which may be the cause of persistent cyanosis, and the discovery of a cleft palate may afford explanation of difficulty in sucking. It is hardly necessary to emphasise the fact that the examination should be carried out as speedily as possible, and the child should not be exposed unduly.

(8) At present, health visitors visit the homes of all newly born infants after the midwives have ceased attendance on the mother and child, i.e., after the 10th or 14th 
day of puerperium. In my opinion this is too late, as the majority of midwives are not sufficiently experienced in the problems of pædiatrics. This difficulty could be overcome by the provision of a domiciliary nursing infant service, whereby nurses sufficiently versed in infant welfare, or health visitors, should be responsible for the care of such infants until they come under the control of a competent infant welfare clinic. Moreover, this provision might be extended to embrace a system whereby a trained nurse might be available for attendance in the home in connection with both minor and major infantile maladies, because however complete and satisfactory the Infant Welfare Centres become, there will still remain the need for skilled nursing and treatment of the sick infant in its own home. Timely attention by a skilled nurse might prevent a relatively minor illness from taking an acute or even fatal course. Particularly is this the case in respiratory diseases and in gastro-enteritis.

(9) As regards medical treatment, the medical attention available for sick babies is not always all that could be desired. Often poverty prevents the mother from calling in a doctor until illness is acute or the sick baby may even be taken out to the doctor's surgery to save the fee for a visit, or to a hospital out-patient department. So that only too often when the doctor arrives it is too late to do much for the baby even if the necessary home treatment can be carried out properly. A combination of prompt medical attention by a doctor who has sufficient knowledge of illness in young children, and of good nursing, seems essential, and the nurse if called in first will always see that the doctor is sent for when needed.

Perhaps the most satisfactory way of ensuring timely medical attention would be by an extension of the arrangements under the National Health Insurance Act to the dependents of insured persons, or by the institution of a State Medical Service.

(10) A further suggestion would be to increase the facilities for hospital accommodation of infants who cannot properly be nursed at home, under conditions which will ensure skilled medical and nursing treatment and safety from dangers of cross infection. Separate cubicles should be provided for each child-the general ward system at present only too common in hospitals is to be condemned for an infants' ward.

(11) Further scientific investigation, study and research of infant hygiene and the diseases of infants and children should be promoted, and better education of medical students, health visitors and midwives in this branch of their curriculum should be encouraged.

(12) Compulsory refresher courses for midwives and health visitors would be urgently stressed, and post-graduate refresher courses for doctors on the panel of the confinement list of local Supervising Authorities are very necessary.

(13) Lastly, extended facilities for the education of the public generally in the importance of securing suitable provision for ante-natal and child welfare services should be provided, with films, talks and the formation of guilds. The educational propaganda should be attractive, tempting and imaginative.

The following is a bibliography, from which liberal references have been made in some instances, and acknowledgments are due to their authors:-

Diseases of Infancy and Childhood. Sheldon. 2nd Edn. Churchill, London.

HAWKSLY \& LIGHTWOOD (1934). Q. J. Med. 3, 155.

Infant Mortality. Reports on Pub. Health \& Med. Subjects. Dame Janet Campbell. (Ministry of Health]Public. No. 55). Stationery Office.

Manual of Obstetrics. Eden \& Holland, 8th Edn. Churchill, London.

McNEIL, C. (1940). Lancet 1,912.

Mothercraft, Ante-natal \& Post Natal. Jewesbury. Churchill, London.

Mothercraft, Ante-natal \& Post Natal. Jewdesbury. Churchill, London.

Public Health. No. 11. Vol. LIII. Aug. 1940.

The Abnormal in Obstetrics. Berkeley, Bonney \& Macleod. Arnold, London. 